\title{
SEXUALIDADE
}

\section{UM CONCEITO PSICANALÍTICO FREUDIANO}

\author{
PAULO BEARZOTI*
}

\begin{abstract}
RESUMO - É realçada a dificuldade em se conceituar sexualidade por ser assunto complexo e controvertido. É apresentada uma conceituação baseada na psicanálise freudiana. Para tanto, muitas das referências de Freud sobre o assunto são reunidas e citadas tendo como fonte a Edição Standard Brasileira das Obras Psicológicas Completas de Sigmund Freud. Assim, pouco a pouco, a seguinte conceituação de sexualidade é elaborada: sexualidade é energia vital ins tinativa direcionada para o prazer, passível de variações quantitativas e qualitativas, vinculada à homeostase, à afetividade, às relações sociais, às fases do desenvolvimento da libido infantil, ao erotismo, à genitalidade, à relação sexual, à procriação e à sublimação.
\end{abstract}

PALAVRAS-CHAVE: sexualidade, conceituação psicanalítica freudiana.

Sexuality: a freudian psychoanalytical concept

SUMMARY - Emphasis is placed in the difficulty in conceptualizing sexuality as a complex and controversial subject. This is a presentation of a concept based on freudian psychoanalysis. With this in mind, many of Freud's references are collected from the Brazilian Standard Edition of the Complete Psychological Works of Sigmund Freud. The following concept is arrived at: sexuality is an instinctive vital energy directed to pleasure, with the possibility of quantitative and qualitative variations, closely bound to homeostasis, to affection, to social relations, to phases of development of childhood-libido, to eroticism, to genitality, to sexual relations, to procreation and to sublimation.

KEY-WORDS: sexuality, freudian psychoanalytical concept.

Sexualidade é assunto complexo, controvertido e de conceituação difícil. Tem sido alvo de tabus, repressões, distorções e tentativas de reduzi-la a sinônimo de genitalidade e de reprodução. Serve para dar vazão a sentimentos elevados como o amor embora permita também que outros, como a agressividade e a violência, possam manifestar-se por meio dela. Sua conceituação depende do ponto de vista considerado: o psicológico, o antropológico, etc. ${ }^{4}$. Na psicologia, a idéia do que seja sexualidade vai depender da escola considerada. Na conceituação a ser elaborada, vou aterme a uma visão psicanalítica freudiana da sexualidade humana e, por esse motivo, Freud (18561939), obviamente, será muito citado. Essas referências encontram-se na Edição Standard Brasileira das Obras Psicológicas Completas de Sigmund Freud; entre parênteses, cito o número dos volumes em algarismos romanos e o número das páginas em algarismos arábicos. O conceito será elaborado por partes e no transcorrer do estudo serão apresentados os argumentos para justificar a inclusão de um determinado aspecto do assunto na conceituação de sexualidade.

O esforço para elaborar uma conceituação psicanalítica freudiana de sexualidade é justificado por vários motivos: que eu saiba, esta conceituação ainda não foi elaborada; a psicanálise, em boa

* Neuropediatra. Aceite: l-agosto-1993. 
parte, está fundamentada sobre a sexualidade; uma conceituação permite identificar melhor os limites e os níveis de sua influência sobre o psiquismo; facilita a reflexão sobre temas como o desenvolvimento da libido na criança, por exemplo.

\section{LIBIDO E OBJETO INSTINTUAL}

O homen tem necessidades sexuais e, para explicá-las, a biologia lança mão do chamado instinto sexual da mesma maneira que, para explicar a fome, utiliza-se do instinto da nutrição. A esta necessidade sexual dá-se o nome de libido (VII: 135, XVI: 336,482). Assim, libido é o tempo que descreve as manifestações dinâmicas da sexualidade (XVIII: 308); é a força motriz da vida sexual (XXII: 161); a libido, forças instintuais da vida sexual (XVI: 482), sofre variações quantitativas (VII: 223) que dependem das transformações que venham a ocorrer na excitação sexual. A libido tem sua origem na energia subjacente aos processos mentais em geral (VII: 223; XIV: 95). Freud atribuiu à libido uma natureza exclusivamente sexual (VII: 223; XIV: 95; XVI: 482). Para ele, a excitação sexual origina-se em todos os órgãos e não somente naqueles denominados sexuais (VII: 223). Ele dá o nome de libido do ego à representação mental de uma quantidade de libido. Quando se leva em conta a produção da libido do ego assim como seu aumento, diminuição, distribuição e deslocamento, criam-se condições que permitem o entendimento dos fenômenos psicossexuais (VII: 223-225).

Objeto de um instinto é tudo aquilo no qual ou por intermédio do qual o instinto atinge sua finalidade. $O$ objeto pode ser parte do corpo, o corpo todo, algo fora do indivíduo, outra pessoa e pode ser modificado quantas vezes forem necessárias dependendo das transformações que o instinto venha a sofrer (XIV: 137-162). Quando um instinto, principalmente nas fases iniciais de seu desenvolvimento, fica muito vinculado ao seu objeto, esta situação é denominada fixação (XIV: 143).

Quando a libido do ego é deslocada para os objetos sexuais eles se tornam investidos de energia libidinosa e, nessas condições, a libido do ego se torna objetai (VII: 223-224). Esta última pode ser retirada de um objeto, ficar em suspenso, ser transferida para outro objeto ou voltar para o ego (VII: 224). Em 1915 Freud referiu-se à libido como uma certa dose de capacidade para o amor que o homem possui sendo que, no início da vida, é dirigida para o próprio ego e só posteriormente é deslocada para os objetos (XIV: 346-347).

\section{CATEXIA}

Catexia refere-se a cargas de energia psíquicas (XX: 304). $O$ termo foi empregado pela primeira vez por Freud em 1913 na discussão de um caso clínico (II: 135). Mas a noção de catexia já existia em seus escritos embora aparecesse sob a forma de expressões tais como, "suprido de energia", "carregado de uma soma de excitação", entre outras, conforme é assinalado pelo coordenador do volume II na introdução escrita por ele (II: 29-32). Já em 1894 Freud referia-se ao conceito de que alguma coisa precisava ser distinguida nas funções mentais - uma cota de afeto ou soma de excitação - que possuía características de quantidade (embora não pudesse ser medida) e com possibilidades de aumentar, diminuir, deslocar-se e descarregar-se; ela percorria os traços de memória das idéias à semelhança da carga elétrica quando se expande sobre a superfície dos corpos (III: 73). Como entender nos dias atuais esta colocação feita por Freud? Talvez, da seguinte maneira: o ponto de encontro entre uma terminação axônica e outra célula nervosa ou entre o axônio e uma célula muscular ou glandular foi denominada de sinapse por Sherrington (18571952). Nas sinapses o potencial de ação é transferido de uma célula para outra. Inicialmente, pensava-se, de maneira errada, que o axônio se ligava firmemente à célula pós-sinapsial. Esta forma de sinapse, conhecida como elétrica, é considerada muito rara. Nos mamíferos e no homem prevalecem as sinapses denominadas químicass. É possível que idéias como essas tenham influenciado Freud levando-o a comparar o deslocamento da cota de afeto com expansão da carga elétrica na superfície dos corpos. Por outro lado, a maneira como Freud expõe a teoria dos neurônios e as barreiras de contato, que podem ser consideradas como sendo as sinapses, (I: 398-403) permite supor que esta interpretação da chamada cota de afeto (catexia) pode ser, pelo menos em parte, válida. Contudo, é bom lembrar que é sempre muito arriscada a tentativa de interpretar o que se passa na mente de um escritor. 
Inicialmente, Freud retrata catexia como entidade material, calcada na estrutura histológica do sistema nervoso e, consequentemente, a idéia de catexia estava atrelada à neurologia; esta visão inicial do assunto é muito bem relatada no apêndice elaborado pelo Editor inglês no volume III (III: 77).

Mais tarde, amplia-se a noção existente sobre a questão com o advento dos conceitos de catexias livre e ligada (XII: 281; XVIII: 51-52,83).

O termo catexia pode ser empregado para indicar: (1) a origem da excitação, p.ex., uma sequência de pensamento pode receber uma catexia de um desejo inconsciente (V: 633; XVII: 98); (2) o deslocamento de cargas energéticas, p. ex., idéias com carga de intensidade débil podem receber um reforço de carga proveniente de idéias fortemente catexiadas (IV: 187); (3) se a carga de energia psíquica é forte ou fraca; (4) a carga de energia psíquica vinculada a objetos (catexia objetai) (XVI: 395); (5) o interesse libidinal que as pessoas têm por seus objetos amorosos (catexia libidinal); por exemplo, uma pessoa doente pode retirar sua catexia do objeto amoroso redirecionando-o para o seu próprio ego até restabelecer-se (XIV: 98). Em termos práticos, catexia pode ser entendida como investimento de energia psíquica.

\section{SEXUALIDADE}

Em um sentido comum e popular, sexualidade é considerada sinônimo de genitalidade assim como vida sexual é tida como equivalente a relação sexual. Freud dá ao termo um significado bem mais amplo situando sexualidade tanto aquém como além do ato sexual (XI: 207-213). Ele prefere falar em psicossexualidade (XI: 208). Freud usa a palavra sexualidade dentro da mesma conotação que na língua alemã se emprega o termo "lieben" (amar) (XI: 209). Sexualidade vai além da reprodução (XVIII: 71; XX: 51-52); Freud identifica o instinto sexual já na infância (I: 372; VI: 240; X: 109,165) e detecta a presença dos germes dos impulsos sexuais no recém-nascido (VII: 181,177, 212; IX: 243-247; XVI: 363, 366; XXIII: 177-181); considera o homossexualismo (XI: 111; XVI: 356-357); leva em conta a sublimação (VII: 245; IX: 193; XIV: 111-112; XV: 36); até nos chistes ele identifica a sexualidade (VIII: 117-122); etc. É preciso salientar, contudo, que uma parte das dificuldades do assunto (sexualidade) decorre do fato de serem os instintos do organismo um tema também complexo e controvertido (XIV: 137-162; XVIII: 51,58; XIV: 55-63).

De agora em diante, uma conceituação psicanalítica freudiana de sexualidade começa a ser montada. Como Freud propôs um modelo energético para o aparelho mental (XXIII: 189), energia é a primeira parcela do conceito: sexualidade é energia.

Agora vamos considerar as crianças recém-nascidas ou as bem pequenas e as variações do meio interno delas. O recém-nascido, aliás, não diferencia o meio interno do externo (XXI: 84-85). Por outro lado, o meio interno tanto da criança como do adulto só pode variar, sem por em risco a vida, se for dentro de certos limites. O organismo possui recursos para identificar e corrigir essas variações do meio interno, é a homeostase. Na criança, a sexualidade está ligada instintivamente a várias funções vitais e à autopreservação (VII: 186; XVI: 204,239,366-415). Se aceitarmos que o termo homeostase abrange a vinculação da sexualidade com a autopreservação, com as necessidades vitais instintivas da criança muito pequena além de englobar sua participação na manutenção do equilíbrio do meio interno da criança e do adulto, podemos ampliar o conceito de sexualidade: $e ́$ energia vital instintiva vinculada à homeostase.

A sexualidade sofre flutuações quantitativas quando ocorrem variações da excitação sexual (VII: 218-222), da tensão sexual e do pré-prazer (VII: 215-218), etc; além disto, outros fatores, como a vergonha, a repressão, as normas sociais vigentes, podem modificar quantitativamente a sexualidade uma vez que restringem o instinto sexual (VII: 238). Em resumo, a sexualidade é passível de variações quantitativas. Com mais este acréscimo, fica assim o conceito de sexualidade: é energia vital instintiva passível de variações quantitativas e vinculada à homeostase. 
É aceito que o potencial de cada indivíduo só se desenvolve adequadamente se ele estiver em um meio social ao lado de outros seres da mesma espécie com os quais possa manter vínculos e relacionamentos, estimulando e sendo estimulado; esta é uma das condições indispensáveis para que ele possa cumprir seu programa pessoal e o da espécie. Está demonstrado também que as várias funções só se atualizam em um determinado momento do desenvolvimento e isto é relativamente fixo para cada espécie, p.ex., na espécie humana existe uma época certa para andar, falar, etc. ${ }^{2}$. Além disto, os eventos biológicos, como a mielinização, têm seus correlatos funcionais, como a aquisição da marcha. Embora os eventos biológicos tendam a ser relativamente fixos, os estímulos ambientais são variados. Dessa forma, fica evidente que as trocas entre a criança, nos vários estágios de seu desenvolvimento, e as demais pessoas de seu ambiente social são de fundamental importância para ela, principalmente, quando são consideradas sua infância prolongada e a sua dependência dos adultos (IX: 187-208, XXII: 86). Em seus estudos de psicologia de grupo Freud, além de realçar o importante papel desempenhado pela sexualidade (XVIII: 91-168, XXI: 119-138), faz a colocação de que os laços libidinais são o que caracteriza um grupo (XVIII: 128). Se aceitarmos que a expressão "relações sociais" contém todas as considerações feitas, podemos avançar na conceituaçao de sexualidade: é energia vital instintiva passível de variações quantitativas, vinculada à homeostase e às relações sociais.

A sexualidade da criança, que é um ser em desenvolvimento, só poderá manifestar-se, num determinado nível de seu desenvolvimento, por meio das estruturas de seu corpo que estiverem relativamente prontas e permeáveis para o escoamento; como exemplo pode ser citada a correlação entre a boca e a fase oral na manifestação da sexualidade infantil nas fases iniciais do seu desenvolvimento. Freud considerou a fase oral como a primeira na organização da libido da criança (XVIII: 74,113). Ele pôs em evidência a sexualidade infantil ao conceber as fases pré-genitais das manifestações da libido na criança: a oral, a sádico-anal, a fálica e a de latência (VII: 177-212). Com este acréscimo, que diz respeito ao desenvolvimento da libido infantil, amplia-se o conceito de sexualidade: é energia vital instintiva passível de variações quantitativas, vinculada à homeostase, às relações sociais e às fases do desenvolvimento da libido infantil. Como o desenvolvimento da sexualidade infantil atinge sua plenitude na genitalidade, amplia-se mais ainda o conceito de sexualidade: é energia vital instintiva passível de variações quantitativas, vinculada à homeostase, às relações sociais, às fases do desenvolvimento da libido infantil e à genitalidade.

O desenvolvimento permite, a partir de um certo momento, que boa parte da energia sexual passe a ser investida em atividades específicas voltadas para a excitação sexual e para o ato sexual propriamente dito (VII: 214-222). Em relação ao ato sexual é preciso ter em mente que a expressão "relação sexual** engloba todo e qualquer objeto sexual envolvido na relação assim como os substitutos dela, p.ex., a masturbação. Introduzindo a expressão "relação sexual" à parcela da conceituaçao de sexualidade já elaborada e aceitando que o termo erotismo engloba a excitação sexual como um todo e, em especial, aquela proveniente das zonas erógenas, amplia-se mais ainda o conceito de sexualidade: é energia vital instintiva passível de variações quantitaivas, vinculada à homeostase, às relações sociais, às fases do desenvolvimento da libido infantil, ao erotismo, à genitalidade e à relação sexual.

Frequentemente, as relações sexuais são mantidas sem finalidades procriativas. Em outras circunstâncias, como fruto delas, uma nova vida é concebida: é a procriação que, por sua vez, garante a preservação da espécie. Com este acréscimo dilata-se mais ainda o conceito de sexualidade: é energia vital instintiva passível de variações quantitativas, vinculada à homeostase, às relações sociais, às fases do desenvolvimento da libido infantil, ao erotismo, à genitalidade, à relação sexual e à procriação. 
Agora é preciso introduzir o conceito de funções integrativas do sistema nervoso central: compreendem, por exclusão, o conjunto das manifestações e atividades que não se encaixam nas funções motoras, nem nas sensitivas, nem nas neurovegetativas. É um conceito muito abrangente que engloba o ciclo vigília-sono, a memória, a cognição, a afetividade, etc. ${ }^{3}$. Os afetos são uma parte relativamente pequena das funções integrativas mas de fundamental importância para todos os homens mesmo porque, como observou Freud, a força mental só adquire sentido quando desperta sentimentos (IX: 55). Por outro lado, é muito profunda a vinculação entre os afetos e a sexualidade (1:259-261,266; II: 253-254,302-306; III: 65,90-91; VII: 209-210). Levando em conta a importância dos afetos e suas vinculações com as manifestações sexuais, fica assim o conceito de sexualidade: é energia vital instintiva passível de variações quantitativas, vinculada à homeostase, à afetividade, às relações sociais, às fases do desenvolvimento da libido infantil, ao erotismo, à genitalidade, à relação sexual e à procriação.

Quando são considerados em conjunto, conforme já foram expostos, os seguintes aspectos da sexualidade: o desenvolvimento da libiddo infantil, as modificações das catexias libidinosas, a variação dos objetos sexuais, os tipos de afetos eliciados nas manifestações sexuais, fica claro que a sexualidade é passível de variações qualitativas. Assim sendo, fica da seguinte maneira o conceito de sexualidade: é energia vital instintiva passível de variações quantitativas e qualitativas, vinculada à homeostase, à afetividade, às relações sociais, às fases do desenvolvimento da libido infantil, ao erotismo, à genitalidade, à relação sexual e à procriação.

O homem, movido por motivações várias, consegue deslocar a libido objetai desviando-a de sua finalidade original, que é a satisfação sexual, para outros objetivos não sexuais: é a sublimação; p.ex., a arte, a amizade, etc. (IX: 193; XIV: 111; XVIII: 116; XXI: 122; XXII: 121). Com este acréscimo, podemos prosseguir na conceituação de sexualidade: é energia vital instintiva passível de variações quantitativas e qualitativas, vinculada à homeostase, à afetividade, às relações sociais, às fases do desenvolvimento da libido infantil, ao erotismo, à genitalidade, à relação sexual, à procriação e à sublimação.

$A$ psicanálise propõe que os eventos mentais são regulados pelo princípio do prazer e, por isso mesmo, em seu curso, buscam atingí-lo (VII: 149; XVIII: 83; XXI: 85, 94). Na infância o instinto sexual é fragmentado, isto é, composto por parcelas, vindo cada uma delas das várias zonas erógenas; só mais tarde ocorrerá a unificação dos vários componentes (XIII: 111-112; XVIII: 297). Cada parcela busca a obtenção do prazer por seus próprios caminhos. O objeto do instinto sexual na infância é o próprio corpo da criança, ou seja, é auto erótico (VII: 240). Quando o desenvolvimento sexual se completa atingindo a vida sexual do adulto, a busca do prazer fica sob a influência da função reprodutora (VII: 203; IX: 194; XV: 52). Freud dá ênfase à culminância que o prazer atinge no ato sexual (XVIII: 83; XXI: 101,121).

Levando em conta todas as considerações feitas até aqui, podemos conceituar sexualidade, finalmente, como se segue: sexualidade é energia vital instintiva direcionada para o prazer, passível de variações quantitativas e qualitativas, vinculada à homeostase, à afetividade, às relações sociais, às fases do desenvolvimento da libido infantil, ao erotismo, à genitalidade, à relação sexual, à procriação e à sublimação.

Agradecimentos - Agradeço ao Dr. John C. Lane a gentileza de ter vertido o resumo e, em especial, a definição de sexualidade para o inglês e ao Dr. Osvaldo D. M. Di Loreto a leitura crítica do trabalho e os comentários feitos.

\section{REFERÊNCIAS}

1. Freud S. Edição stantard brasileira das obras psicológicas completas de Sigmund Freud. Rio de Janeiro: Imago Editora, 1970-1977.

2. Gesell A, Amatruda YC. Diagnóstico del desarrollo normal y anormal del niño. Ed 2. Buenos Aires: Editorial Paidos, 1962.

3. Schimdt RE (org.). Neuro fisiologia. São Paulo: EPU-SPRINGER-EDUSP 1979, 80: 303-349.

4. Silva B, Miranda AG Netto et al (Eds.). Dicionário de ciências sociais. Ed 2. Rio de Janeiro: Editora da Fundação Getúlio Vargas, 1987. 